\title{
Analisis Gaya Bahasa Sarkasme Lagu "Suci Maksimal” oleh Musisi Jason Ranti
}

\author{
Andar Dittya Harsa, Gregorius Genep Sukendro \\ andardittyaharsa@gmail.com,geneps@fikom.untar.ac.id \\ Fakultas Ilmu Komunikasi Universitas Tarumanagara
}

\begin{abstract}
In Indonesia, there are many famous musicians, one of whom is Jason Ranti, with his language style, Jason Ranti is able to represent what listeners feel in each of his songs. This study aims to determine the language style of the song "Suci Maximum" to the reader. This study uses a qualitative method. In this study using the technique hermeneutika. The theory used in this study, namely the theory of sarcasm by linking song verses with the types of sarcasm. Song as mass communication and construction. This research uses descriptive qualitative research methods. The research results were obtained from online sources about the song "Suci Maksimal" and related to Jason Ranti as the writer. The song "Sacred Maximum" by Jason Ranti is a style of sarcasm. Sarcasm has 4 types: Propositional Sarcasm, Lexical Sarcasm, Like - Prefixed Sarcasm, and Illocutionary Sarcasm. The Sacred Song Maximum has a different type of sarcasm in each verse. However, the dominant style of sarcasm was used with Jason Ranti to emphasize the meaning of the Maximum Sacred song, Propositional Sarcasm, because in some stanzas written that contain Propositional Sarcasm elements tend to be striking.
\end{abstract}

Keywords: lyrics, mean, sarcasm.

\begin{abstract}
Abstrak
Indonesia memiliki banyak musisi yang terkenal salah satunya Jason Ranti. Dengan gaya bahasanya, Jason Ranti mampu mewakili pendengar di setiap lagunya. Penelitian ini bertujuan untuk mengetahui gaya bahasa dalam lirik lagu "Suci Maksimal". Penelitian ini menggunakan metode kualitatif. Dalam penelitian ini menggunakan teknik hermeneutika. Teori yang dipakai dalam penelitian ini, yaitu teori sarkasme dengan mengaitkan bait lagu dengan jenis-jenis sarkas. Lagu sebagai komunikasi massa dan konstruksi. Penelitian ini menggunakan metode penelitian kualitatif deskriptif. Hasil penelitian diperoleh dari sumbersumber online mengenai lagu "Suci Maksimal" dan berhubungan dengan Jason Ranti selaku penulis. Lagu "Suci Maksimal" dari Jason Ranti termasuk gaya bahasa sarkasme. Gaya bahasa sarkasme memiliki 4 jenis yaitu propositional sarcasm, lexical sarcasm, like-prefixed sarcasm, dan illocutionary sarcasm. Lagu Suci Maksimal memiliki jenis sarkas yang berbeda di setiap baitnya. Namun gaya bahasa sarkasme yang dominan digunakan dengan Jason Ranti untuk menekankan arti dari lagu "Suci Maksimal" yaitu propositional sarcasm. Pada beberapa bait yang ditulis unsur propositional sarcasm cenderung mencolok.
\end{abstract}

Kata Kunci: lirik, makna, sarkasme.

\section{Pendahuluan}

Di Indonesia banyak musisi perorangan maupun kelompok yang menjadikan musik sebagai media kritik terhadap aspek sosial ataupun politik yang sedang terjadi di masyarakat. Beberapa musisi Indonesia yang kerap menyampaikan kritik sosial dan politik yaitu Iwan Fals, Slank, Efek Rumah Kaca, Jason Ranti, dan lain-lain. Musik adalah salah satu cara dalam melakukan komunikasi melalui suara (audio) 
dengan cara yang berbeda. Musik mampu menyuarakan dalam menyampaikan pesan dari berbagai fenomena, isu, serta topik-topik yang mempunyai pengaruh dengan kehidupan masyarakat. (Khairil, 2017).

Dalam penelitian Toat Kurniawan yang berjudul Analisis Gaya Bahasa Ironi dan Pesan Moral Lagu-Lagu Slank dalam Album AntiKorupsi Tinjauan Semiotik pada tahun 2009 mengutip kalimat Bahari (2008: 14-15) bahwa sebuah karya seni dibuat atau diciptakan bukan sekedar untuk ditampilkan, dilihat, dan didengar saja, tetapi harus dengan gagasan, abstraksi, pendirian, pertimbangan, hasrat, kepercayaan, serta pengalaman tertentu yang hendak dikomunikasikan penciptanya. Realitas sosial, tema, ideologi, dan teknik pengelolaan musik saling berkaitan dalam membentuk pesan dan kritik.

Pencipta lagu menyampaikan pesan melalui lirik lagu. Salah satu pencipta lagu yang menyampaikan kritik terhadap realitas sosial masyarakat yaitu Jason Ranti. Pesan dalam lagu yang dibuat oleh Jason Ranti memiliki makna sarkasme dan tersirat. Beberapa lagu Jason Ranti seperti "Kafir", "Bahaya Komunis", dan "Suci Maksimal" masing-masing lagu tersebut memuat isu-isu yang terkait dengan realitas sosial di masyarakat. Isu-isu tersebut seperti pencitraan pejabat, diskriminasi agama, dan isu neokomunisme. Lagu yang dibuat oleh Jason Ranti memiliki hubungan antara lirik lagu dengan menyampaikan kritik terhadap realitas sosial yang terjadi di masyarakat.

Kritik dalam lirik lagu Jason Ranti memiliki makna sarkasme. Kata sarkasme berasal dari bahasa Yunani yaitu Sarkasmos yang diturunkan dari kata kerja sakasein yang berarti merobek-robek daging seperti anjing, menggigit bibir karena marah, atau bicara dengan kepahitan. Sarkasme sejenis bahasa yang mengandung sindiran pedas dan menyakiti hati (Afrinda, 2017, hal 64)

Di Indonesia, kreativitas semakin berkembang, salah satunya dengan musisi yang membuat lirik lagu dengan kesan menyentil orang-orang penting. Penelitian Monica dan Sukendro berjudul "Analisis Kreativitas Cindercella dalam Melakukan Make Up Art" mengutip Utami Munandar, kreativitas adalah suatu hasil interaksi antara individu dan lingkungannya, serta kemampuan untuk membuat kombinasi baru, berdasarkan data, informasi, maupun unsur yang sudah ada atau dikenal sebelumnya, yaitu dengan semua pengetahuan dan pengalaman seseorang yang telah diperoleh melalui lingkungan sekitarnya dan dapat dikombinasikan menjadi suatu hal yang baru. Tidak semua manusia memiliki kreativitas dan juga tidak semua manusia yang memiliki kreativitas memiliki keberanian untuk menuangkan kreativitasnya dalam bentuk seni ataupun sebuah lirik lagu.

Jason Ranti sudah banyak membuat lagu yang diperuntukan untuk pejabat, organisasi masyarakat, bahkan agama dengan gaya bahasa yang sarkas dan nada pembacaan liriknya yang kontemporer. Tetapi dengan lirik dan nada bahasa yang berbeda dengan musisi lainnya. Popularitas Jason Ranti meroket di panggung nasional, bahkan sudah mempunyai penggemar atau fanbase yang bernama "Gerombolanwoyoo". Popularitas yang diraih Jason Ranti dikarenakan banyak orang yang sepaham dengan Jason Ranti. Jason Ranti muncul dengan membawa beberapa lagu yang bisa menyentil oknum-oknum di Indonesia. 
Penelitian ini ingin meneliti lagu "Suci Maksimal". Lirik yang dibuat oleh Jason Ranti di lagu ini ingin menyentil para pejabat nakal. Lagu ini mewakili suara banyak orang yang sependapat dengan Jason Ranti. Seperti penggalan liriknya berikut:

\section{“Kulihat TV, pak penjahat safari moral}

\section{Ku baca koran, pak penjahat banyak simpenan}

\section{Kebanyakan cinta”}

Pada lirik tersebut, Jason Ranti ingin mengkritik pejabat yang membuat citra baik di depan masyarakat, padahal di media lain pejabat tersebut bertindak asusila atau melecehkan perempuan. Kekesalan Jason Ranti melihat para pejabat yang dipilih rakyat tetapi mempermainkan tahta pejabat untuk kepentingan pribadi disampaikan melalui lirik lagu "Suci Maksimal". Masih banyak lagi lirik yang menyentil para penjahat berdasi dan baju berkilau. Berdasarkan latar belakang dan identifikasi masalah tersebut, peneliti ingin mengetahui gaya bahasa sarkasme dalam lagu "Suci Maksimal" oleh Jason Ranti. Teori yang digunakan dalam penelitian ini adalah teori sarkasme yang terdiri dari empat jenis, yaitu: propositional sarcasm, lexical sarcasm, 'like'-prefixed sarcasm, dan illocutionary sarcasm.

\section{Metode Penelitian}

Melakukan penelitian kualitatif, terdapat tiga jenis penelitian kualitatif, yaitu format deskriptif, format verifikatif, format grounded research. Format deskriptif lebih tepat apabila digunakan untuk meneliti masalah-masalah yang membutuhkan studi mendalam, seperti permasalahan tingkah laku konsumen suatu produk, masalah-masalah efek media terhadap pandangan pemirsa terhadap suatu tayangan media, permasalahan implementasi kebijakan publik di masyarakat dan sebagainya. Data dikumpulkan dalam format deskriptif adalah berupa kata-kata, gambar, dan bukan angka-angka. Laporan penelitian berisi kutipan-kutipan data untuk memberi gambaran penyajian laporan. Data tersebut mungkin berasal dari naskah wawancara, catatan lapangan, foto, videotape, dokumen pribadi, catatan atau memo, dan dokumen resmi lainnya. Metode Hermeneutika menjadi metode yang menjelaskan arti lirik lagu "Suci Maksimal" yang sesungguhnya menjadi bahasa yang sederhana. 


\section{Hasil Temuan dan Diskusi}

Tabel 1. Lirik Suci Maksimal dengan Jenis Sarkasme

\begin{tabular}{|c|c|}
\hline Bait Lirik & Jenis Sarkasme \\
\hline Uu.. pak penjahat, naik haji setahun sekali & Lexical Sarcasm \\
\hline Uu.. bu penjahat, cuci kaki satu jam sekali & Lexical Sarcasm \\
\hline Suci maksimal & Illocutionary Sarcasm \\
\hline Uu.. pak penjahat, cita - cita jadi robin hood & Lexical Sarcasm \\
\hline $\begin{array}{l}\text { Uu.. bu penjahat, angan - angan mati di } \\
\text { pantai, mati maksimal }\end{array}$ & Lexical Sarcasm \\
\hline $\begin{array}{l}\text { Merah kuning hitam putih kelabu, jalan } \\
\text { hidup mu sungguh kelabu, }\end{array}$ & 'Like'-Prefixed Sarcasm \\
\hline apakah tidur mu puas? lama dan pulas & 'Like'-Prefixed Sarcasm \\
\hline $\begin{array}{l}\text { Mimpi mu indah? panjang dan luas, atau } \\
\text { gelap dan buas }\end{array}$ & 'Like'-Prefixed Sarcasm \\
\hline Kulihat TV, pak penjahat safari moral & Propositional Sarcasm \\
\hline $\begin{array}{l}\text { Kubaca koran, pak penjahat banyak } \\
\text { simpanan kebanyakan cinta }\end{array}$ & Propositional Sarcasm \\
\hline Doanya kencang, jahatnya tetap & Propositional Sarcasm \\
\hline Hatinyahitam. Baju berkilau & Propositional Sarcasm \\
\hline
\end{tabular}

Sumber: Dokumentasi Peneliti (2020)

Hasil analisis yang telah dipaparkan sebelumnya dengan peranan hermeneutika dalam teks lagu "Suci Maksimal" karya Jason Ranti. Hermeneutik bertujuan untuk memahami melalui metode abduksi, bukan hanya menafsirkan. Interpretasi (penafsiran) selalu merupakan rekonstruksi makna sebuah teks.

Lagu "Suci Maksimal" diciptakan oleh Jason Ranti pada tahun 2017. Jason Ranti atau yang sering disapa dengan panggilan Jeje, berhasil mengeluarkan single "Suci Maksimal" yang mengekspresikan apa yang Jeje rasakan pada saat itu. Single "Suci Maksimal" keluar setelah sebulan merilis album "Akibat Pergaulan Blues" .Jeje merasa harus 'menyentil' para tokoh agamis tersebut yang berperilaku kriminal karena sudah muak dengan yang mereka lakukan.

Lagu "Suci Maksimal" termasuk salah satu komunikasi dengan memiliki tujuan artistik guna menghasilkan ungkapan seperti dalam cerita, kisah, syair, puisi, gambar, musik, pahat - pahatan. Musik adalah salah satu jenis komunikasi, karena musik mengandung lirik dan instrumen yang menggambarkan komunikasi dari pencipta ke pendengar. Instrumen menggambarkan komunikasi karena dari gaya instrument sudah mengetahui gaya komunikasi yang ingin disampaikan. Lirik menggambarkan komunikasi karena pencipta menulis lirik dengan gaya bahasa yang berbeda-beda, gaya bahasa yang digunakan Jason Ranti dalam lagu "Suci Maksimal" yaitu gaya bahasa sarkasme.

Pertama adalah latar belakang memproduksi teks. Pencipta lagu "Suci Maksimal", yaitu Jason Ranti merupakan pencipta sekaligus mengaransemen lagunya sendiri. Jeje banyak membuat lagu dengan menggunakan kata yang sedikit menyentil. Jason Ranti merupakan penyair hebat di kalangan Indie musik. Aransemen dan lirik yang dibuatnya berbeda dengan musik-musik indie lainnya. Tujuannya adalah agar para pendengar lagu "Suci Maksimal" mengetahui bahwa jangan menilai orang dengan mudah dari penampilan. Seperti berbuat baik di depan, mencitrakan dirinya di televisi maupun di media lainnya, mengajak masyarakat untuk menurunkan orang jahat yang menjabat. Jeje mengkritik bahwa politik di 
Indonesia saat ini menilai agama nomor satu daripada apa yang telah ia capai, makanya banyak oknum tokoh agamis yang memanfaatkan keadaan.

Pada penggalan bait pertama yang berbunyi Uu.. Pak penjahat, naik haji setahun sekali merupakan gambaran seorang pria dewasa berperilaku kriminal, tetapi menutupinya dengan beribadah. Pada analisis makna unsur teks, bait pertama berbunyi Uu.. Pak penjahat, naik haji setahun sekali seorang laki-laki tokoh agamais yang menjalankan ibadah rajin tetapi ia berprilaku kriminal. Seseorang beribadahnya jalan terus tetapi berbuat jahatnya juga tetap.

Pada penggalan bait kedua yang berbunyi $U u$.. Bu penjahat, cuci kaki satu jam sekali, Suci Maksimal seorang perempuan dewasa yang berperilaku kriminal, yang menggambarkan dirinya selalu bersih. Pada analisis makna unsur teks, bait kedua berbunyi Uu.. Bu penjahat, cuci kaki satu jam sekali Suci Maksimal seorang perempuan yang membersihkan dirinya setiap satu jam agar tidak kotor, padahal yang kotor ialah hatinya yang berbuat kriminal atau berperilaku jahat.

Pada penggalan bait ketiga yang berbunyi Uu.. Pak penjahat cita - cita jadi robin hood: seorang pria dewasa berperilaku kriminal yang berkeinginan melawan pejabat yang korupsi untuk kepentingan rakyat. Pada analisis makna unsur teks, bait ketiga yang berbunyi Uu.. Pak penjahat cita - cita jadi robin hood merupakan tokoh agamis yang berkeinginan menjadi seorang pahlawan, yang membela rakyatnya, seperti Robin Hood yang korupsi untuk kepentingan rakyat. Banyaknya pemimpinpemimpin baru yang mencari bangku untuk menjadi pahlawan masyarakat.

Pada penggalan bait keempat yang berbunyi $U u$.. Bu penjahat angan - angan mati di pantai, mati maksimal seorang perempuan dewasa berperilaku kriminal yang berkeinginan meninggal dengan indah, meninggal yang sangat indah. Pada analisis makna unsur teks, bait keempat yang berbunyi $U u$.. Bu penjahat angan - angan mati di pantai, mati maksimal, menceritakan kehidupan seorang penjahat yang melakukan kriminal yang hidupnya indah, bahkan meninggalnya saja ingin di tempat yang indah dan luas, mereka dapat melakukan apa saja yang diinginkan dengan uang.

Pada penggalan bait kelima yang berbunyi Jalan hidup mu sungguh kelabu: kehidupan yang samar-samar. Pada analisis makna unsur teks, bait kelima yang berbunyi Jalan hidup mu sungguh kelabu mereka mempunyai hidup yang tidak jelas, yang kadang mencitrakan dirinya dengan agama, dan terkadang mereka berprilaku kriminal, mereka masih memuaskan dirinya di dunia dengan uang dan kepuasan.

Pada penggalan bait keenam yang berbunyi Apakah tidur mu puas? lama dan pulas menanyakan tidur seorang kriminal yang bisa beristirahat dengan tenang dan nyenyak. Pada analisis makna unsur teks, bait keenam yang berbunyi apakah tidur mu puas? lama dan pulas mereka yang melakukan kriminal atau berperilaku jahat yang tentunya untuk wanita, uang, dan tahta. Mereka akan tertidur puas dan nyenyak.

Pada penggalan bait ketujuh yang berbunyi Mimpi mu indah? Panjang dan luas atau gelap dan buas: menanyakan mimpi seorang kriminal yang indah atau bermimpi buruk karena melakukan hal kriminal. Pada analisis makna unsur teks, bait ketujuh yang berbunyi Mimpi mu indah? Panjang dan luas atau gelap dan buas mereka yang melakukan kriminal bermimpi indah karena mereka punya segalanya, atau bahkan mereka tidak bisa tidur karena bermimpi buruk. Tentunya kehidupan mereka yang berprilaku kriminal dan jahat tidak akan tenang hidupnya.

Pada penggalan bait kedelapan yang berbunyi Kulihat TV, pak penjahat safari moral; seseorang pria dewasa yang berbuat kriminal tersebut, selalu tampil di tv untuk pencitraan. Pada analisis makna unsur teks, bait kedelapan yang berbunyi 
Kulihat TV, pak penjahat safari moral para penjahat tersebut, terus mencitrakan dirinya di TV dan media lainnya, agar terlihat hidupnya suci tanpa prilaku kriminal dibalik itu semua, cara ini sudah banyak yang dipakai oleh para pelaku kriminal di Indonesia.

Pada penggalan bait kesembilan yang berbunyi Ku baca koran, pak penjahat banyak simpenan kebanyakan cinta; bapak tersebut ternyata punya banyak perempuan simpanan untuk memenuhi hasratnya. Pada analisis makna unsur teks, bait kesembilan yang berbunyi Kubaca koran, pak penjahat banyak simpenan kebanyakan cinta; ternyata dibalik pencitraan mereka didepan layar kaca yang mensucikan dirinya kepada masyarakat, malah berbuat kriminal dengan bermain cinta dengan perempuan. Tentunya amat disayangkan mereka yang menganggap dirinya suci di depan, namun hatinya hitam yang terus berbuat kejahatan.

Pada penggalan bait kesepuluh yang berbunyi Doanya kencang, jahatnya tetap: beribadah rajin tetapi tetap melakukan hal kriminal. Pada analisis makna unsur teks, bait kesepuluh yang berbunyi Doanya kencang, jahatnya tetap; mereka beribadah dengan baik, tetapi mereka melakukan kejahatan yang tentunya merugikan banyak orang. Karena mereka yang dianggap seorang pemimpin tentunya punya pengikut, karena pengikut menganggap bahwa pemimpin mereka adalah orang suci yang memang harus menjadi pemimpin.

Pada penggalan bait kesebelas yang berbunyi Hatinya hitam, baju berkilau: dalam hatinya jahat tetapi tertutup dengan ibadah yang rajin Pada analisis makna unsur teks, bait kesebelas yang berbunyi Hatinya hitam, baju berkilau: bahwasanya mereka yang berperilaku kriminal dan jahat selalu menutupi dengan pencitraan bahwa diri mereka amat suci. Karena bagi mereka jadi baik di depan tentunya mereka akan dipercaya dan dipercaya tidak akan melakukan hal jahat. Ternyata dibalik kesucian mereka tentunya mereka masih melakukan hal - hal yang tidak patut dijadikan contoh siapapun.

Lagu "Suci Maksimal" menegaskan bukan dasar orang yang beragama yang berkaitan dengan lagu tersebut, orang yang mencitrakan dirinya baik di depan namun buruk dibelakang. Banyak kasus di Indonesia yang dilakukan oleh pemimpin pemimpin di Indonesia, seperti kasus korupsi, penggelapan dana anggaran, dan hal hal yang tak terpuji lainnya. Jason Ranti ingin menyentil para pemimpin-pemimpin yang dipercayai baik oleh masyarakat karena perilaku terlihat baik didepan masyarakat, tetapi malah menyalahgunakan kepercayaan masyarakat tersebut dengan melakukan hal-hal yang tidak terpuji. Jason Ranti menyuarakan sekaligus mewakili masyarakat terhadap mereka pemimpin-pemimpin yang melakukan hal terpuji tersebut, banyaknya kasus-kasus korupsi, penggelapan uang yang tentunya merugikan masyarakat Indonesia. Karena itu Jason Ranti gemas dengan ulah-ulah pemimpin Indonesia yang seperti itu.

Lagu "Suci Maksimal” karya Jason Ranti salah satu lagu yang sangat baik, karena mampu menyentil pemimpin - pemimpin yang melakukan hal tidak terpuji. Teks lagu yang frontal di lagu "Suci Maksimal" menggambarkan keresahan masyarakat atas tingkah mereka yang buruk. Karya-karya Jason Ranti yang banyak lirik - lirik yang menyentil tentunya banyak menyuarakan masyarakat, oleh karena itu Jason Ranti salah satu musisi yang kontemporer. Karena kebebasan berpendapat itu boleh dengan media apa saja, atau bebas, dengan lagu Jason Ranti banyak membuat kata-kata yang menyentil, walaupun banyak memakai kata sarkas.

Jason Ranti menulis teks lagu dilakukan secara natural dan mengalir begitu saja, hingga tidak jarang juga dia tidak menyimpulkan apapun dari apa yang dia 
tulis. Jadi ketika ada orang yang bertanya tentang arti dibalik lagunya, maka pilihannya ada dunia, antara dia memang benar-benar tidak tahu arti dibalik itu, atau dia tahu, tapi dia tidak ingin memberitahunya. Pada prakteknya menurut dia, yang sering terjadi biasanya Jason Ranti menjawab asal saja sekenanya pertanyaan tersebut dengan iseng, tapi memasang mimik muka yang serius. Hal ini bukan tanpa alasan, karena menurutnya lagu itu bisa dimaknai bebas sesuai pemahaman pendengarnya. Dia tidak menginginkan ada interpretasi tunggal dari lagu yang dia buat, atau menurut istilah yang dituturkan oleh Jason Ranti, dia tidak mau karyanya menjadi mati karena interpretasinya dibatasi.

Menurut Jeje lagu yang dibuat cukup serius, hanya saja penonton yang merespon menganggap lirik-lirik yang dibuat menjadi sebuah candaan, karena liriklirik yang dibuat Jason Ranti tidak biasa, berbeda dengan band-band lainnya, menggunakan kata-kata sarkas dan kontemporer.

Jason Ranti membuat lagu tidak hanya dari isu-isu yang sedang naik, tetapi Jason Ranti menulis lagu karena yang ada dipikirannya saja, menurutnya masih ada ruang-ruang lain yang bisa dipikirkan. Lagu "Suci Maksimal" terbentuk banyak terkait dengan kasus-kasus yang terjadi dengan politisi di Indonesia, karena menurut Dr. Tompi di acara Narasi TV "lagu itu akan mencari takdirnya sendiri" jadi lagu "Suci Maksimal" ini menyuarakan hal-hal yang terjadi pada kejadian tersebut.

Dengan lirik yang terdengar kritis dan sangat mungkin dipolitisir Jason Ranti pun merasa takut, karena menurutnya orang jahat banyak. Tetapi ia tidak merasa bersalah, ia pun tidak berencana untuk itu (takut terus berubah). Menurutnya orang misal ingin bikin khilafah, berbicara di hadapan ribuan orang pakai pengeras suara, mereka percaya diri. Jadi ia merasa biasa-biasa saja.

\section{Simpulan}

Jason Ranti menciptakan lagu "Suci Maksimal" didasari kegelisahan terhadap orang yang menilai orang lain hanya dari 'kulit luar'-nya saja. Pada dasarnya segala atribut yang dikenakan seseorang sebenarnya adalah atribut duniawi. Menurutnya, agama terletak di hati. Lagu "Suci Maksimal" banyak menyentil bapak atau ibu yang berperilaku buruk dan merugikan orang lain, dengan dibungkus katakata sarkasme pada liriknya. Lagu "Suci Maksimal" menjadi lagu yang mewakili keresahan-keresahan masyarakat terhadap seseorang yang merugikan orang lain tersebut. Pada analisis hermeneutika pada teks lagu "Suci Maksimal", terbagi menjadi lima bagian yaitu, makna unsur-unsur pembentukan teks, makna teks berdasarkan latar belakang memproduksi teks, makna teks berdasarkan lingkungan teks, makna teks berdasarkan kaitan dengan teks lain, dan makna teks berdasarkan dialog teks dengan pembaca.

Lagu "Suci Maksimal" dari Jason Ranti termasuk gaya bahasa sarkasme. Gaya bahasa sarkasme memiliki emat jenis yaitu Propositional Sarcasm, Lexical Sarcasm, Like - Prefixed Sarcasm, dan Illocutionary Sarcasm. Lagu Suci Maksimal memiliki jenis sarkas yang berbeda di setiap baitnya. Namun gaya bahasa sarkasme yang dominan digunakan dengan Jason Ranti untuk menekankan arti dari lagu Suci Maksimal yaitu Propositional Sarcasm, karena di beberapa bait yang ditulis yang mengandung unsur Propositional Sarcasm cenderung mencolok.

Makna judul "Suci Maksimal" sendiri ialah menggambarkan bahwa seseorang yang merasa dirinya bersih dan tidak pernah berperilaku buruk yang berdampak merugikan orang lain, di lirik lagu "Suci Maksimal" yang 
menggambarkan keresahan Jason Ranti terhadap orang yang menilai orang lain dengan 'kulit luar'nya berbunyi hatinya hitam, baju berkilau bahwasanya mereka yang berperilaku kriminal dan jahat selalu menutupi dengan pencitraan bahwa diri mereka suci. Karena bagi mereka jadi baik di depan tentunya mereka akan dipercaya dan dipercaya tidak melakukan hal jahat. Ternyata dibalik kesucian mereka tentunya mereka masih melakukan hal-hal yang tidak patut dijadikan contoh siapapun. Makna hermeneutika lagu "Suci Maksimal" bertujuan untuk mengetahui makna sarkasme yang Jason Ranti tuliskan di lirik lagu "Suci Maksimal". Kaitan musik dengan advertising atau iklan yaitu musik merupakan salah satu pendukung atau iklan langsung, iklan langsung dari musik yang disebut jingle. Iklan juga bisa didukung oleh musik, atau yang disebut backsound.

\section{Ucapan Terima Kasih}

Terimakasih kepada orang-orang yang telah membantu untuk penelitian ini dari awal hingga terakhir sehingga penelitian ini dapat terjadi.

\section{Daftar Pustaka}

Bungin, Burhan. (2009). Konstruksi Sosial Media Massa: Kekuatan Pengaruh Media Massa, Iklan Televisi, dan Keputusan Konsumen Serta Kritik Terhadap Peter L. Berger \& Thomas Luckmann. Jakarta: Kencana.

Bungin, Burhan. (2013). Konstruksi Sosial Media Massa: Kekuatan Pengaruh Media Massa, Iklan Televisi, dan Keputusan Konsumen Serta Kritik Terhadap Peter L. Berger \& Thomas Luckmann. Jakarta: Kencana.

Danesi, M. (2010). Pengantar Memahami Semiotika Media. Yogyakarta: Jalasutra.

Enzim. (2012). Analaisis Data Metodelogi Penelitian Kualitatif. Jakarta: RajawaliPers

Hamdju, Atan. (1987). Buku Pengetahuan Seni Musik. Jakarta: PT. Mutiara Sumber Widya.

Heryanto, Ariel. (2015). Identitas dan Kenikmatan: Politik Budaya Layar Indonesia. Jakarta: Gramedia.

Moleong, Lexy J. (2013). Metodologi Penelitian Kualitatif. Bandung: PT. Remaja Rosdakarya.

Nazir, Moh. (2011). Metode Penelitian. Bogor: Penerbit Ghalia Indonesia

Pradopo, Rachmat Djoko. 2012. Pengkajian Puisi. Yogyakarta: Gadjah Mada University Press.

Ricoeur, Paul. 1981. Paul Ricoeur Hermeneutics and The Human Sciences. English: Cambrige University Press.

Semi, Atar. 1998. Kritik Sastra. Bandung: Angkasa.

Sobur, A. (2003). Semiotika Komunikasi. Bandung: Rosadakarya.

Waluyo, Herman J. 1995. Apresiasi Puisi Untuk Pelajar dan Mahasiswa. Jakarta: PT Gramedia Pustaka Utama.

Dinari, Irene. Jenis - Jenis Dan Penanda Majas Sarkasme Dalam Novel The Return Of Sherlock Holmes. Universitas Sebelas Maret. Diakses dari : https://jurnal.uns.ac.id/prosidingprasasti/article/download/230/212 
Monica. (2019). Analisis Kreativitas Cindercella dalam Melakukan Make Up Art. Jurnal Komunikasi Prologia. Vol. 3, No. 1, Juli 2019, Hal 196- 203

Pratama, Edo. (2019). Representasi Keberagaman Dalam Lirik Lagu Jason Ranti (Analisis Wacana Kritis Pada Lirik Lagu Jason Ranti). Fakultas Ilmu Sosial Dan Ilmu Politik. Universitas Lampung. Diakses dari : http://digilib.unila.ac.id/60201/3/SKRIPSI\%20TANPA\%20BAB\%20PEMB AHASAN.pdf

Rachman, Haidir. (2013). Kajian Hermeneutika Teks Lagu "Kompor Meleduk" Karya Benyamin Sueb. Fakultas Sastra Indonesia. Universitas Nasional. Diakses dari https://www.academia.edu/3432290/KAJIAN_HERMENEUTIKA_TEKS LAGU_KOMPOR_MELEDUK_KARYA_BENYAMIN_SUEB https://m.detik.com/hot/main-stage/d-3679936/cerita-jason-ranti-tentang-lagu-sucimaksimal 